\title{
The Association between Public Transportation and Social Isolation in Older Adults: A Scoping Review of the Literature
}

\author{
Madeline Lamanna, ${ }^{1}$ C Christopher A. Klinger, ${ }^{2,3}$ Anna Liu, ${ }^{3}$ and Raza M. Mirza ${ }^{2,3}$
}

\begin{abstract}
RÉSUMÉ
Le manque de transports en commun adéquats a été identifié comme un frein à la participation sociale, en particulier chez les adultes plus âgés vivant en communautés rurales et pour ceux ayant des problèmes de mobilité. Les personnes âgées ne peuvent profiter des occasions d'engagement offertes dans leur communauté ou maintenir des réseaux sociaux si elles ne peuvent y avoir accès. L'objectif de cette revue de littérature était de formuler des recommandations pour d'éventuelles recherches et de présenter les domaines où des améliorations sont nécessaires, selon ce qui a été rapporté dans la littérature, afin d'appuyer le développement d'initiatives de transport public contribuant à diminuer l'isolement social des adultes plus âgés (55 ans et plus). Les critères d'inclusion ont permis de sélectionner dix-neuf articles abordant les thèmes de l'accès aux transports publics ruraux, les défis du transport public et la mobilité. Dans la pratique, les aînés doivent se préparer aux transitions associées au fait de ne plus pouvoir conduire et aux pertes de mobilité. L'élaboration de politiques adéquates nécessite des consultations en vue de créer des initiatives de transport adaptées à la population vieillissante. De plus amples recherches devraient être menées pour explorer les besoins des personnes âgées en matière de transport et identifier de possibles solutions dans les communautés urbaines et rurales.
\end{abstract}

\begin{abstract}
Inadequate public transportation was recognized as a barrier to social participation, especially for older adults in rural communities and with mobility issues. Older adults will not benefit from opportunities to engage with their community and maintain social networks if they are unable to access them. The purpose of this scoping review was to make recommendations for further research and to summarize areas for improvement identified in the literature that will aid in the development of public transportation initiatives that can better address social isolation for older adults ( $\geq 55$ years of age). Nineteen articles met the inclusion criteria, identifying themes of access to rural public transportation, issues with public transportation, and mobility. In practice, older adults need to prepare for driving cessation and mobility transitions; sound policy requires input to tailor transportation initiatives to an aging population, and future research should explore older adults' transportation needs and potential solutions in urban and rural communities.
\end{abstract}

1 Health Studies Department, University College, University of Toronto, Toronto, Ontario.

2 Institute for Life Course and Aging, Factor-Inwentash Faculty of Social Work, University of Toronto, Toronto, Ontario.

3 National Initiative for the Care of the Elderly, Toronto, Ontario.

* This article was written in partial fulfillment of the requirements for the HST451 Health Studies Independent Research Course at the University of Toronto's University College. Preliminary results from this scoping review were presented as a research poster at the University College Research and Practice Day in March 2018 (by M.L.). M.L. thanks the Health Studies Department at the University of Toronto for the opportunity to complete an independent research project in her undergraduate career. She also thanks the University of Toronto's Library System and her librarian contact, Judith Logan, for her support. The authors thank the anonymous reviewers for their invaluable contribution in enhancing the clarity and flow of this article. The authors have no conflict of interest to declare.

Manuscript received: / manuscrit reçu : 14/01/18

Manuscript accepted: / manuscrit accepté : 01/04/19

Mots-clés : vieillissement, adapté aux personnes âgées, examen de la portée, isolement social, transport en commun Keywords: aging, age-friendly, scoping review, social isolation, public transportation 
La correspondance et les demandes de tire-à-part doivent être adressées à : / Correspondence and requests for offprints should be sent to:

Madeline Lamanna, B.Sc.

Health Studies Department

University College

University of Toronto

15 King's College Circle

Toronto, Ontario, M5S $3 \mathrm{H} 7$

Canada

(madeline.lamanna@mail.utoronto.ca)

\section{Introduction}

Older adults are at an increased risk for social isolation, which is indicated by a decrease in the size of one's social network, a lack of engagement with others, and a smaller number of social contacts who provide physical, social, and emotional support (CloutierFisher, Kobayashi, \& Smith, 2011; Coyle \& Dugan, 2012; Nicholson, 2009). Older adults often experience diminishing social networks and a lack of engagement because of higher rates of disability and disease, mobility issues, and life transitions, such as retirement and death of spouses, family members, and friends (Coyle \& Dugan, 2012; Nicholson, 2012). In turn, social isolation puts older adults at an increased risk for heart disease (Boden-Albala, Litwak, Elkind, Rundek, \& Sacco, 2005), cognitive decline (Béland, Zunzunegui, Alvarado, Otero, \& del Ser, 2005), and dementia (Fratiglioni, Wang, Ericsson, Maytan, \& Windblad, 2000).

These life changes, and risk of isolation, are sometimes exacerbated by challenges not only related to mobility, but also to accessibility with respect to modes of transportation. Existing literature often discusses public transportation in relation to older adults experiencing driving cessation, which led to their reliance on other modes of transportation to maintain their lifestyle and social engagement (Curl, Stowe, Cooney, \& Proulx, $2014^{1}$ ). When older adults were often reluctant to give up driving, it was because they viewed it as a loss of independence and autonomy (Adler \& Rottunda, 2006; Liddle \& McKenna, 2003), therefore leading to feelings of depression (Chihuri et al., 2016; Ragland, Satariano, $\&$ MacLeod, 2005) or to feeling that they were a burden to family and/or friends (Adler \& Rottunda, 2006; Davey, 2007). Older adults also experienced numerous barriers to using public transportation such as lack of accessibility, affordability, frequency, and reliability; existing literature discussed these barriers and the improvements that need to be made to public transportation (Adler \& Rottunda, 2006; Bryanton, Weeks, \& Lees, 2010푸 ; url et al., 20141; Nordbakke \& Schwanen, 2015; World Health Organization , 2007).

In addition, the World Health Organization's (WHO) Age-Friendly Community and City (AFC) movement has successfully promoted healthy aging and has enhanced quality of life by providing a framework to reduce social isolation and loneliness (World Health Organization, 2007). Participating cities/communities adapted to meet the physical and social needs of older adults by addressing the WHO's eight AFC dimensions: outdoor spaces and buildings, transportation, housing, respect and inclusion, social participation, civic participation and employment, communication and information, and community supports and health services (World Health Organization, 2007). AFCs have provided older adults with opportunities to volunteer, engage with their communities, and participate in activities that facilitate meaningful social connections, thereby reducing social isolation (Emlet \& Moceri, 2012). Furthermore, the WHO (2007) recognized transportation as a key factor that may underscore an older adult's ability to participate in social and civic activities and health care.

Despite discussion of the use of public transportation after driving cessation, issues with public transportation that impact older adults, and research such as that by the WHO that addressed social isolation, there was a lack of information about how public transportation is associated with social isolation (Adler \& Rottunda, 2006; Bryanton et al., 2010'; Curl et al., 20141; Liddle \& McKenna, 2003; Nordbakke \& Schwanen, 2015; World Health Organization, 2007). For example, the scoping review that was conducted by Levasseur et al. $\left(2015^{1}\right)$ looked at elements of the built environment (including public transportation) and social participation. Levasseur et al. $\left(2015^{1}\right)$ found that inadequate public transportation was one of many factors that hindered social participation; however, the present scoping review looked at public transportation alone and how it is associated with social isolation. From the point of view of the public transportation literature, transportation initiatives are often not examined in relation to social isolation. Similarly, in social isolation literature, public transportation is often considered part of the built environment or considered alongside other types of transportation. Therefore, this research provided a starting point for the development of public transportation initiatives that can directly address social isolation. 
The purpose of this scoping review was to gain an understanding of how public transportation is associated with social isolation and to provide recommendations for how social isolation can be considered when designing and implementing public transportation initiatives. The aim was to identify broad recommendations that can be applied and tailored to the unique needs of communities locally, nationally, and across the globe. The results of this scoping review provide specific practice, policy, and research recommendations for public transportation initiatives that address social isolation in older adults.

\section{Methods}

This research project used a scoping review approach to summarize existing literature and research findings, to identify gaps that exist in the literature, and to disseminate research, policy, and practice implications from the literature (Arksey \& O'Malley, 2005; Levac, Colquhoun, \& O'Brien, 2010). The existing literature on this topic was reviewed using Arksey and O'Malley's (2005) five-step methodological framework for conducting a scoping review: identifying the research question; identifying relevant studies; study selection; charting the data; and collating, summarizing, and reporting results. The optional sixth stage (Arksey \& O'Malley, 2005), which involves consultation with an expert panel to provide additional insight into the development of the research question and to assist with the understanding of the research findings, was not used, because of time constraints.

\section{Stage 1: Identifying the Research Question}

The research question that was explored in this scoping review was: What is the association between public transportation and social isolation for older adults ( $\geq 55$ years of age)? This question evolved following a preliminary search of the literature. To address the specific gap in the existing literature, public transportation, as opposed to personal transportation, was the focus of this scoping review. As Nicholson (2009) concluded, social isolation is a concept that encompasses a variety of definitions, and many factors can be used to measure it. However, social isolation generally includes characteristics such as a lack of belonging, social engagement, social contacts, and fulfilling and meaningful relationships (Nicholson, 2009). Therefore, various terms were used in place of "social isolation", such as "social integration", "social networks", and "social engagement" (Nicholson, 2009). The goal of a scoping review is to gain a broad understanding of all the available literature related to a topic; therefore, there were various search terms used to gain a full representation of the term "social isolation" (Arksey \& O'Malley, 2005). No weighing of the evidence was performed to allow for a broader view. The final search terms and the search strings used for each database can be found in Appendix 1.

\section{Stage 2: Identifying Relevant Studies}

Both peer-reviewed and grey literature databases were included in the literature search to locate a wide variety of articles to be used in the scoping review. The eight peer-reviewed databases consisted of: Ageline, ASSIA: Applied Social Sciences Index and Abstracts, Compendex, GEOBASE, Social Sciences Abstracts, Social Services Abstracts, Social Work Abstracts, and Transport Database. The three grey literature sources were articles available on the Health Canada Web site and on ProQuest Dissertations \& Theses Global, and a custom Google search of Canadian government documents. The flow chart of the articles included in the scoping review by database can be found in Appendix 2.

\section{Stage 3: Study Selection}

Two reviewers (M.L., A.L.) worked separately to screen the titles and abstracts after using the search terms to find articles in the peer-reviewed and grey literature databases. The reviewers applied the inclusion and exclusion criteria (see the next section) to determine the final articles used in the scoping review. Then, two reviewers working together (R.M.M., C.A.K.) were prepared to resolve any disagreement between the first and second reviewers about the selection of the final articles. The first and second reviewer met to discuss any differences of opinion and came to an agreement about the final articles; therefore, the third reviewers did not need to resolve any discrepancies.

\section{Inclusion and Exclusion Criteria}

The inclusion criteria consisted of articles discussing participants $\geq 55$ years of age of any gender, race, and/ or ethnicity; peer-reviewed and grey literature articles; studies located in any country; and studies focused on public transportation and factors such as social isolation, social participation, and social engagement. The $\geq 55$ year age range was chosen to define the population of older adults based on the preliminary searches of the literature, which demonstrated that this age threshold allowed for the broadest scope of relevant articles to be included in the scoping review. Articles from any country and including participants from any ethno-cultural background were eligible because all older adults, regardless of where they live or what their background is, are at risk for social isolation (Cloutier-Fisher et al., 2011; Coyle \& Dugan, 2012; Nicholson, 2009). Both peerreviewed and grey literature articles were used to gain a broad understanding of the research available; both dissertations and government documents (from all 
levels of government) were included in this scoping review. Finally, the last inclusion criterion was for the studies to focus on the association between public transportation and social isolation, to provide an understanding of the available literature relevant to the research question stated previously.

The exclusion criterion consisted of studies not in English. The requirement for the articles to be written in English was because the principal investigator was only fluent in English.

The grey literature articles from the custom Google search of Canadian government documents were sorted by relevance within the section of the Web site that included documents from all levels of government. Then, the titles and text previews were screened for terms related to older adults, public transportation, and/or social isolation. Only articles deemed relevant based on their titles and text previews were included in the final data extraction. This process took place alongside the screening of the peer-reviewed literature's titles and abstracts. The scoping review articles were identified and selected between October 2017 and December 2017. Please see Appendix 2 for the results of the application of inclusion and exclusion criteria to determine the final articles used in the scoping review.

\section{Stage 4: Charting the Data}

Microsoft Excel (Microsoft Corporation, United States of America) was used to chart the data and to summarize the articles that were included in the scoping review. The chart listed: author(s), year of publication, database, journal or grey literature source, location of the study, participants included, methodology used, outcomes and the important results (findings that were relevant to the research question), and key themes. Please see Appendix 3 for the extraction table of the final scoping review articles, organized alphabetically.

\section{Stage 5: Collating, Summarizing, and Reporting Results}

Key themes were deduced from the final scoping review articles using thematic content analysis (TCA). TCA is a qualitative analysis methodology in which themes are summarized and compared (Anderson, 2007). The primary investigator (M.L) generated themes. The key themes were listed in the summary chart after each of the final articles was read and themes that described the article were identified (Anderson, 2007). TCA allowed for articles to be grouped based on key themes that were relevant to the research question and the discussion of public transportation issues. Terminology or descriptor words from the articles were used as names for the themes. Finally, implications for practice, policy, and research were determined based on the findings of the articles (Arksey \& O'Malley, 2005; Levac et al., 2010). An overview is presented in Appendix 4.

\section{Results}

The process for determining the final articles for inclusion in the scoping review is explained subsequently, followed by a description of the articles' characteristics. Next, results surrounding the articles' findings toward the association between social isolation and public transportation are discussed to examine how they are relevant to the research question. Finally, themes in the literature are reported before highlighting the themes in depth and discussing how these themes can inform research, policy, and practice recommendations in the Discussion section.

The search strategy of the eight peer-reviewed databases and three grey literature sources resulted in 397 potential articles to be used in the scoping review. After 13 duplicate articles were removed, the titles and abstracts of 384 articles were screened using the inclusion and exclusion criteria. This resulted in 357 articles that did not meet the inclusion criterion for articles to have a focus on public transportation and social isolation (or related factors), and 5 articles that did not meet the inclusion criterion for participants in the studies being $\geq 55$ years of age; therefore, these articles were not included in the final scoping review. Furthermore, three articles met the exclusion criterion because they were not written in English; therefore, these articles were also eliminated. A total of 19 articles were included in the scoping review (see Appendix 2 for a depiction of the complete process).

Of the 19 final articles, most were peer-reviewed articles $(n=14)$, the others were grey literature $(n=5)$ : three were reports by the Government of Canada and two were dissertations. Most of the articles were from the United States of America $(n=9)$, followed by studies that were from Canada $(n=8)$; one was from the United States of America and Canada, and one was from various European countries including Finland, Germany, Hungary, Italy, and The Netherlands (see Appendix 3). The methodology used in these articles consisted of quantitative techniques: five studies used a crosssectional survey/questionnaire (Bittner, Fuchs, Baird, \& Smith, 2011; Chaudhury, Mahmood, Michael, Campo, \& Hay, 20121; Gagliardi et al., 20071; Rittner \& Kirk, 19951; Salazar, 19991) and Geographic Information System (GIS) mapping (Kotval-K, 2017¹), and qualitative techniques: four studies used focus groups (Bittner et al., 2011'; Federal/Provincial/Territorial Ministers Responsible for Seniors, 2007a ${ }^{1}$; Mullen, $2005^{1}$; Salazar, 199911), five studies used interviews (Bittner et al., 2011'; Bryanton et al.,

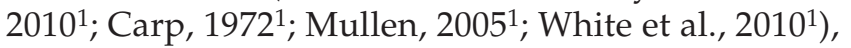


one used a meeting with experts (Federal/Provincial/ Territorial Ministers Responsible for Seniors, 2007b ${ }^{1}$ ), and one used a photovoice method in which participants took photographs of their environment to visually demonstrate the physical or social barriers or facilitating factors of their neighbourhoods (Chaudhury et al., $\left.2012^{1}\right)$. Six studies used a literature review, which can be classified as a prerequisite to quantitative and/or qualitative studies (Bittner et al., 2011'; Federal/Provincial/ Territorial Ministers Responsible for Seniors, 2007b ${ }^{1}$; Kotval-K, 2017'; Public Health Agency of Canada, 2010 ; Salazar, 19991'; Woldeyohannes, 2016¹). Additionally, secondary data analysis techniques toward both quantitative (Bittner et al., 2011'; Curl et al, 2014 ${ }^{1}$; Kim, 2011'; Kotval-K, 2017') and qualitative (Curl et al., 2014¹) data were used. Finally, one of the studies was a scoping study itself (Levasseur et al., 2015ํ), one was a research report with recommendations (Community Transportation Association of America, 2007¹), and the other one was a research article summarizing the results of another study (Klassen \& Allen, 2005'). All three of these articles included findings from quantitative and qualitative literature. Please see Appendix 3 for a summary of the studies' characteristics.

\section{Public Transportation and Social Isolation}

All included articles discussed public transportation and social isolation in tandem. Public transportation was often included in a discussion of modes of transportation for older adults (Bittner et al., 2011'; Bryanton et al., 2010ㄹ; Federal/Provincial/Territorial Ministers Responsible for Seniors, 2007a ${ }^{1}$; Federal/Provincial/Territorial Ministers Responsible for Seniors, 2007b ${ }^{1}$; Gagliardi et al., 2007'; Kim, 2011푸 Kotval-K, 20171; Levasseur et al., $\left.2015^{1}\right)$. Many $(n=9)$ of the articles discussed the use of public transportation after driving cessation (Bittner et al., 2011'; Bryanton et al., 20101' Carp,1972 ${ }^{1}$; Curl et al., 20141; Kim, 2011'; Kotval-K, 20171; Levasseur et al., 20151; Mullen, 20051'; Salazar, 199911); in contrast, four of the articles discussed how older adults often relied on other modes of transportation more often than public transportation (Bryanton et al., 20101; Federal/Provincial/ Territorial Ministers Responsible for Seniors, 2007a ${ }^{1}$; Kim, 2011'; Salazar, 1999¹). In fact, Bryanton and colleagues $\left(2010^{1}\right)$ found that public transportation was not used as an alternative method of transportation by any of the study's participants, and Salazar $\left(1999^{1}\right)$ found that most participants did not use public transportation often and did not plan to use it more often. Conversely, one study suggested that the use of public transportation did not always result from being unable to drive; depending on the season or activity, older adults who can drive choose to use public transportation (Bittner et al., $2011^{1}$ ) instead.
Only six of the articles specifically discussed social isolation (Bryanton et al., 20101; Federal/Provincial/ Territorial Ministers Responsible for Seniors, 2007b ${ }^{1}$; Kotval-K, 2017'; Mullen, 2005'; Public Health Agency

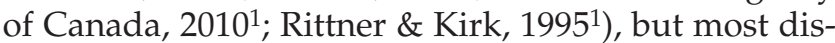
cussed factors associated with social isolation. Furthermore, one article discussed how social exclusion can be facilitated by public transportation that does not meet the needs the elderly (Community Transportation Association of America, 20071). Of the nineteen final articles, most $(n=14)$ discussed how transportation, including public transportation, could potentially remove barriers to remaining socially engaged through opportunities for: volunteering and employment (Bittner et al., 2011'; Federal/Provincial/Territorial Ministers Responsible for Seniors, 2007a ${ }^{1}$; White et al., 2010 ${ }^{1}$ ), recreational and physical activities (Chaudhury et al., 20121 ; Federal/Provincial/Territorial Ministers Responsible for Seniors, 2007a ${ }^{1}$; Gagliardi et al., 20071; Klassen \&

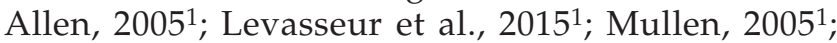
White et al., 20101 , Woldeyohannes, 2016 ${ }^{1}$ ), social activities (Federal/Provincial/Territorial Ministers Responsible for Seniors, 2007a ${ }^{1}$; Gagliardi et al., 2007'; Klassen \& Allen, 20051; Mullen, 2005풀 Rittner \& Kirk, 19951; White et al., 201011), attending community events or accessing community resources (Bittner et al., 2011'; Federal/Provincial/Territorial Ministers Responsible for Seniors, 2007b ${ }^{1}$; Klassen \& Allen, 2005 ${ }^{1}$ ), social participation and engagement (Bittner et al., 2011'; Federal/Provincial/Territorial Ministers Responsible for Seniors, 2007a ${ }^{1}$; Federal/Provincial/Territorial Ministers Responsible for Seniors, 2007b ${ }^{1}$; Levasseur et al., 2015'; Public Health Agency of Canada, 2010¹), accessing support systems of family and friends (Bittner et al., 2011'; Federal/Provincial/Territorial Ministers Responsible for Seniors, 2007a ${ }^{1}$; Kim, 2011; Rittner \& Kirk, 19951 White et al., 2010¹), participating in programs (Chaudhury et al., 2012 ${ }^{1}$; Klassen \& Allen, 2005 $)$, and visiting centres for older adults (Kotval-K, 2017'1).

\section{Themes}

This scoping review revealed three dominant themes in the literature, which indicated that improvement and/or availability of rural public transportation $(n=10)$, addressing issues with public transportation $(n=14)$, and tackling challenges for less mobile older adults $(n=9)$ would allow them to remain socially engaged and to participate in social and community activities

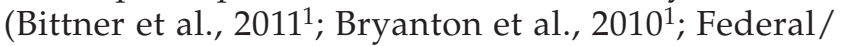
Provincial/Territorial Ministers Responsible for Seniors, 2007a ${ }^{1}$; Federal/Provincial/Territorial Ministers Responsible for Seniors, 2007b¹; Gagliardi et al., 2007'; Kim, 2011'; Levasseur et al., 2015 ${ }^{1}$; Public Health Agency of

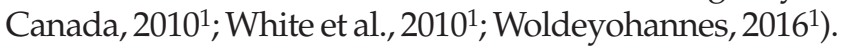


Further discussion of each of these themes is provided in the next sections.

\section{Rural Public Transportation}

Ten of the 19 final articles highlighted the theme of issues with rural public transportation. Discussion of rural/remote communities and public transportation occurred in six of these articles (Bittner et al., 2011'; Bryanton et al., 2010¹; Federal/Provincial/Territorial Ministers Responsible for Seniors, 2007a ${ }^{1}$; Federal/ Provincial/Territorial Ministers Responsible for Seniors, 2007b'; Kotval-K, 20171; Public Health Agency of Canada, 2010 ${ }^{1}$ ), while three of the articles compared rural and urban public transportation (Curl et al., 20141; Gagliardi et al., 20071; Klassen \& Allen, 2005'), and a comparison between high- and low-density neighbourhoods was made in one article (Chaudhury et al., 2012 ${ }^{1}$ ). The concept of neighbourhood density was considered to be relevant because rural communities can be defined by total population, proximity to cities, and/or population density (Statistics Canada, 2008).

Eight articles demonstrated how public transportation was unavailable or more limited in rural communities than in urban communities (Bittner et al., 2011'; Bryanton et al., 20101; Chaudhury et al., 2012 ${ }^{1}$; Curl et al., 2014 ${ }^{1}$; Federal/Provincial/Territorial Ministers Responsible for Seniors, 2007a ${ }^{1}$; Federal/Provincial/Territorial Ministers Responsible for Seniors, $2007 \mathrm{~b}^{1}$; Klassen \& Allen, 2005' Kotval-K, 20171). Therefore, older adults living in rural and/or remote areas were at greater risk for experiencing social isolation as a result of their geographic location, especially if they did not own/no longer owned a car (Bryanton et al., 2010¹; Federal/ Provincial/Territorial Ministers Responsible for Seniors, 2007a ${ }^{1}$; Public Health Agency of Canada, 2010¹). One article found that having access to a car was essential to older adults in rural communities because public transportation did not meet their needs (Chaudhury et al., 2012 $)$. Older adults who lived in rural areas and could not/no longer drive themselves often experienced social isolation if family or friends were not available to drive them (Bryanton et al., 201011). However, family and friends usually only drove older adults to medical appointments or grocery stores, not to social activities (Bryanton et al., 20101).

Public transportation in rural communities was deemed deficient in terms of scheduling (Chaudhury et al., 2012 ${ }^{1}$; Federal/Provincial/Territorial Ministers Responsible for Seniors, 2007a $\left.\mathrm{a}^{1}\right)$, service to recreation and social activities (Chaudhury et al., 20121; Federal/Provincial/ Territorial Ministers Responsible for Seniors, 2007a ${ }^{1}$; Kotval-K, 2017¹), cost (Bittner et al., 2011¹), reliability (Klassen \& Allen, 2005ํ), and walking distance to transit stops (Bittner et al., 2011; Kotval-K, 2017¹). However, one of the most discussed issues was that public trans- portation was often entirely unavailable in rural areas

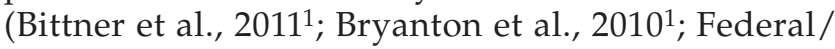
Provincial/Territorial Ministers Responsible for Seniors, 2007a ${ }^{1}$; Federal/Provincial/Territorial Ministers Responsible for Seniors, 2007b ${ }^{1}$; Kotval-K, 2017¹).

\section{Issues with Public Transportation}

Most of the 19 articles $(n=14)$ raised general issues with public transportation experienced by older adults

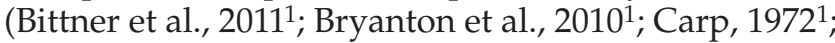
Community Transportation Association of America, $2007^{1}$ Curl et al., 2014루 ; Federal/Provincial/Territorial Ministers Responsible for Seniors, 2007a ${ }^{1}$; Federal/ Provincial/Territorial Ministers Responsible for Seniors, 2007b ${ }^{1}$; Klassen \& Allen, 2005; Levasseur et al., 2015; Mullen, 2005ㄹ ; Public Health Agency of Canada, 2010 ${ }^{1}$; Rittner \& Kirk, 1995'; Salazar, 19991; Woldeyohannes, $2016^{1}$ ). These articles discussed issues such as: accessibility (Bittner et al., 2011' Bryanton et al., 20101; Community Transportation Association of America, 2007; Curl et al., 2014¹; Federal/Provincial/Territorial Ministers Responsible for Seniors, 2007a ${ }^{1}$; Federal/Provincial/ Territorial Ministers Responsible for Seniors, 2007b ${ }^{1}$; Klassen \& Allen, 2005ㄹ ; Levasseur et al., 2015' Mullen, 2005ㄹ Public Health Agency of Canada, 2010¹), affordability (Bittner et al., 2011'; Community Transportation Association of America, 2007¹; Curl et al., 20141; Federal/Provincial/Territorial Ministers Responsible for Seniors, 2007a ${ }^{1}$; Public Health Agency of Canada, 2010¹), frequency (Bryanton et al., 2010¹; Carp, 19721; Federal/Provincial/Territorial Ministers Responsible for Seniors, 2007a ${ }^{1}$; Rittner \& Kirk, 1995'), availability (Bittner et al., 2011ㄹ ; Community Transportation Association of America, 20071; Federal/Provincial/Territorial Ministers Responsible for Seniors, 2007a ${ }^{1}$; Klassen \& Allen, 2005' ; Levasseur et al., 2015'; Public Health Agency of Canada, 2010 ${ }^{1}$ ), efficiency (Levasseur et al., 2015 ${ }^{1}$; Salazar, 19991), adequacy and appropriateness (Federal/ Provincial/Territorial Ministers Responsible for Seniors, 2007b ${ }^{1}$; Levasseur et al., 2015 ${ }^{1}$; Mullen, 2005루 ; Salazar, 19991), consistency (Bittner et al., 2011'1 Rittner \& Kirk, 19951), and convenience (Carp, 1972 ${ }^{1}$; Federal/Provincial/ Territorial Ministers Responsible for Seniors, 2007a ${ }^{1}$; Klassen \& Allen, 2005ํㅜㅇ Salazar, 1999¹).

Specifically, older adults wanted public transportation that has information about scheduling and routes available and is easy to use and navigate (Bittner et al., 2011'; Bryanton et al., 2010¹; Community Transportation Association of America, 2007¹; Federal/Provincial/ Territorial Ministers Responsible for Seniors, 2007a ${ }^{1}$ ). Accessibility was often an issue for older adults; for example, public transit was not available in close proximity to older adults and they had to walk far to

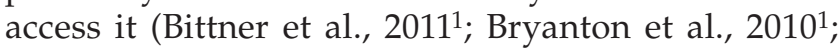

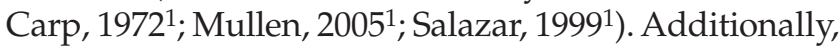


transit stops were not clearly marked (Bittner et al., $2011^{1}$ ), did not have shelters and/or benches (Bittner et al., 2011'1 Mullen, 2005'; Rittner \& Kirk, 19951), or did not have pedestrian crossings near transit stops/ stations (Bittner et al., 2011²).

Other general issues identified by older adults included public transit that did not serve entire municipalities

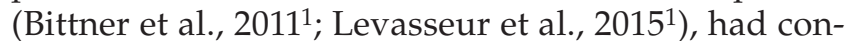
nectivity issues and transfers (Bittner et al., 2011'; Federal/Provincial/Territorial Ministers Responsible for Seniors, 2007a ${ }^{1}$ ), and/or was not coordinated among different transportation systems or municipalities (Bittner et al., 2011'; Community Transportation Association of America, 2007' Federal/Provincial/Territorial Ministers Responsible for Seniors, 2007a ${ }^{1}$; Klassen \& Allen, 2005¹). Specific issues that affected older adults included: public transit without options for use outside of peak hours (Bittner et al., 2011'; Federal/Provincial/ Territorial Ministers Responsible for Seniors, 2007a ${ }^{1}$; Mullen, 20051); public transit that did not provide access to destinations that benefit older adults' social engagement including social activities, family/friends, recreational activities, religious activities, and community events (Bittner et al., 2011'; Federal/Provincial/ Territorial Ministers Responsible for Seniors, 2007a ${ }^{1}$; Mullen, 20051' Salazar, 19991); and public transit that was not promoted as a transportation alternative in the community (Federal/Provincial/Territorial Ministers Responsible for Seniors, 2007a ${ }^{1}$ ).

Two of the articles found that after driving cessation, older adults' participation in volunteering, employment, and social engagement became reduced over time (Bryanton et al., 2010'; Curl et al., 2014¹). When public transit did not meet the needs of older adults as an alternative form of transportation, they had to find other modes of transportation or they did not attend social events or remain engaged in their community (Bryanton et al., 2010루 Carp, 1972 ${ }^{1}$; Curl et al., 2014 ${ }^{1}$ ). Two articles stated that poor public transportation that did not meet the needs of older adults can reinforce their social exclusion from the community (Community Transportation Association of America,

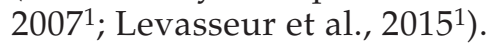

\section{Mobility Issues}

The discussion of mobility issues occurred in 9 of the 19 final articles; the older adult age group had a high prevalence of mobility issues (Bittner et al., 2011'; Chaudhury et al., 2012 ${ }^{1}$; Curl et al., 2014루 ; Gagliardi et al., 2007¹; Klassen \& Allen, 20051; Levasseur et al., 2015'; Mullen, 2005' ; White et al., 20101; Woldeyohannes, 2016 ${ }^{1}$ ).

One article discussed the interaction among mobility issues, transportation, and social networks (Curl et al., $\left.2014^{1}\right)$. The authors found that when older adults experienced reductions in mobility and stopped driving, they were less likely to interact with geographically distant members in their social network. However, the article revealed that older adults might experience more interaction with family and friends who assist them, because these people become the older adults' mode of transportation (Curl et al., 2014¹).

Five articles discussed public transit as a mechanism that can help older adults with various mobility issues to access or hinder them from accessing resources for social interaction and participation (Bittner et al., 2011'; Chaudhury et al., 2012푸 ; Gagliardi et al., 20071'; Klassen \&

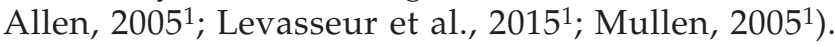
According to one article, it was critical for public transportation to provide access to recreational programs for older adults, because this age group experienced more mobility issues that created barriers to attending recreational programs (Woldeyohannes, 2016¹). Older adults with mobility issues often had to find their own private transportation (e.g., shared-ride public transportation services) to and from social/recreational programs (Klassen \& Allen, 20051). When fixed-route public transportation was not accessible, it created a strain on alternative transportation services (Mullen, $2005^{1}$ ). Two articles discussed public transit as a mechanism of transportation that can help these older adults with various mobility issues to access programs/activities and to maintain their independence (Chaudhury et al., 2012 ${ }^{1}$; Mullen, 2005 $)$. Another article described the different mobility requirements needed to participate in different activities, and found that older adults participated in hobbies, activities, and sports if they were in better health; however, older adults who used public transit, regardless of their mobility level, also participated in more activities outside the home (Gagliardi et al., 20071) in general.

Three articles discussed how transportation could hinder less mobile older adults' social participation (Bittner et al., 2011'; Levasseur et al., 2015¹). Physical mobility issues and disabilities limited transportation options for older adults; for example, older adults might not be able to physically board public transit or walk to transit stops and stations (Bittner et al., 2011'; Mullen, 2005ํ). Similarly, older adults with mobility impairments would not make use of public transit if they did not feel safe or they could not access it easily and safely, even if public transportation was available to them (Levasseur et al., 2015¹).

The outcome of having access to public transportation for older adults with mobility issues was discussed in two articles (Levasseur et al., 2015푸 ; White et al., 2010¹). Older adults who experienced mobility issues but had access to public transportation reported fewer barriers to visiting family and/or friends (White et al., 2010 ${ }^{1}$ ), 
volunteering (White et al., 2010 ${ }^{1}$ ), participating in recreational activities (White et al., 2010 ${ }^{1}$ ), and participating in social activities (Levasseur et al., 20151; White et al., $2010^{1}$ ), and were more mobile (Levasseur et al., 2015²) than those without access to public transportation.

\section{Discussion}

Public transportation for older adults and reducing the likelihood of older adults' experiencing social isolation are often discussed as separate issues; therefore, it was not completely unexpected to see few articles explicitly discuss these two topics in relation to one another. Therefore, this scoping review attempted to consolidate research exploring the relationship between public transportation and social isolation, and to provide recommendations for practice, policy, and research.

To be benefiting from the programs, resources, and services that allow them to engage with their community and to build and/or maintain social networks, older adults need to be able to access the resources that have been established for them (World Health Organization, $2007^{1}$ ). Older adults were not able to make use of opportunities to establish and maintain their social networks if public transportation did not provide service to recreation or social activities, or enable access to their social contacts (Chaudhury et al., 20121; Federal/Provincial/ Territorial Ministers Responsible for Seniors, 2007a ${ }^{1}$; Kotval-K, 2017¹). Social isolation can subsequently be prevented through the facilitation of social networks, encouraging engagement with others, and offering opportunities for building quality social contacts and connections through social participation (Cloutier-Fisher et al., 2011; Coyle \& Dugan, 2012; Nicholson, 2009).

\section{Driving Cessation}

Older adults felt like a burden when they depended on others to drive them places when they could not drive anymore or chose not to drive (Bryanton et al., 20101; Curl et al., 20141; Federal/Provincial/Territorial Ministers Responsible for Seniors, 2007a1 $)$. Older adults chose to stop attending social activities because they did not want to trouble their family or friends for a ride because, unlike medical appointments or visiting the grocery store, social activities were not seen as necessary for them to attend (Bryanton et al., 2010ㄹ; Mullen, 2005). Older adults began to view social activities as a "want" instead of a "need," and it became less essential when they needed to rely on others to drive them (Bryanton et al., 20101). Similarly, Mullen (2005 ${ }^{1}$ ) found that when older adults limited their social participation because of an inability to drive or a choice not to drive, isolation, loss of independence, and the loss of social/recreational activities had a negative impact on their quality of life. Public transit not only affected access to opportunities for socialization and allowed people to maintain contact with society and others, it also increased life satisfaction, self-esteem, and quality of life (Salazar, 1999¹).

\section{Insufficient Public Transit}

This could contribute to social isolation by creating barriers to accessing social networks and remaining socially engaged. There was often a correlation between lack of accessible transportation and feelings of social isolation and loneliness (Rittner \& Kirk, 1995¹). For example, barriers were created when services were scheduled in a way that did not serve older adults in off-peak hours (Federal/Provincial/Territorial Ministers Responsible for Seniors, $2007 \mathrm{a}^{1}$ ), or when it underserved towns/areas/cities or services were completely non-existent, especially in rural communities (Bittner et al., 2011'; Bryanton et al., 2010¹; Federal/Provincial/ Territorial Ministers Responsible for Seniors, 2007a ${ }^{1}$; Federal/Provincial/Territorial Ministers Responsible for Seniors, 2007b ${ }^{1}$; Klassen \& Allen, 20051). The Province of Québec in Canada has made progress in resolving issues with access to public transportation in rural municipalities / areas (Gouvernement du Québec, 2010). Québec ensured that resources for private transportation were pooled with those for public transportation to offer transportation that served all communities (Gouvernement du Québec, 2010). Without available or suitable public transportation, rural older adults who could not drive or chose to no longer drive faced further barriers when they did not have someone to drive them, and other services (e.g., taxis) were unavailable or too expensive to use regularly (Bryanton et al., 2010루 ; Federal/Provincial/Territorial Ministers Responsible for Seniors, 2007a ${ }^{1}$; Klassen \& Allen, 2005 ${ }^{1}$; Kotval-K, 20171).

Likewise, mobility issues also created further barriers when public transportation was available to older adults, because they would not use it if deemed unsafe and/or inaccessible (Levasseur et al., 2015²). Public transportation, therefore, acted as a barrier to social participation when it was inadequate. This led to a reliance on paratransit services (door-to-door services provided by public transportation organizations for people with disabilities who cannot use regular transit), private transportation from family/friends, and/or volunteer transportation services (Mullen, 2005¹). Although the older adults who were interviewed by Mullen $\left(2005^{1}\right)$ might have found another method of transportation that was inexpensive, they did not always have access to paratransit and/or volunteer transit services because of the distance they lived relative to these services or the scheduling of volunteer transportation to/ from programs and activities (Mullen, 20051). Additionally, older adults did not always want to rely on family / friends for private transportation (Mullen, 2005ํ). 


\section{Communication among Stakeholders}

Bittner and colleagues $\left(2011^{1}\right)$ claimed that attempts to improve transportation for older adults often fell short because of a lack of communication among service providers, local agencies, communities, and the regional government. However, successful programs, such as the ones of the Wisconsin Department of Transportation (WisDOT), took older adults' input into account when reviewing transportation solutions (Bittner et al., $2011^{1}$ ). Therefore, successful programs and models to improve transportation for older adults, such as the Specialized Transportation Assistance Program for Counties in Wisconsin, included a requirement for local and regional authorities to communicate with each other and the public to foster collaboration and collective goals (Bittner et al., 2011¹).

Québec, Canada is another example of a province that has recognized the need for communication between stakeholders in transportation planning (Gouvernement du Québec, 2010). The Government of Québec took a unique approach to public transportation through coordination among municipalities, transportation providers, and the provincial government. Municipalities, in partnership with transportation providers that wish to provide transportation solutions to their area, must send a proposed bylaw for approval by the minister of transport of Québec before it can be implemented (Gouvernement du Québec, 2010). Municipalities in Québec often created intermunicipal partnerships, whereby connections among transportation systems were established to provide seamless transit between neighbouring regions. Furthermore, the Government of Québec deemed that any municipality without access to public transit or paratransit must implement solutions to develop appropriate transportation for people with disabilities. The public transportation system in Québec is an example of how the provincial government and regional actors can work in unison to provide public transit to all, excelling at providing solutions for rural areas and people with disabilities (such as older adults with mobility issues) (Gouvernement du Québec, 2010).

\section{Implications for Practice}

The findings of this scoping review highlighted driving cessation as a life transition that often led to reductions in social participation (Bittner et al., 2011'; Curl et al.,

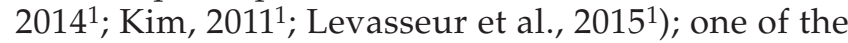
articles suggested that programs be created to help older adults plan for driving cessation (Bryanton et al., $2010^{1}$ ). These programs could enable older adults to learn about their various transportation options after driving cessation, especially as many older adults are unaware of all the options available to them (Bittner et al., 2011'
Bryanton et al., 20101). Such programs could allow older adults to plan for their transition and feel in control of their situation by making the process of driving cessation less abrupt (Bryanton et al., 2010¹). Additionally, these programs would educate older adults about the impact that the processes of aging, mobility issues, disabilities, and diseases have on driving, helping them to decide for themselves when or if they should stop driving (Bryanton et al., 2010¹). Likewise, early intervention when mobility transitions occur or when health conditions are developing could provide older adults with knowledge about how to remain engaged in their community and the transportation options that are available to enable them to do so, helping them to maintain independence that people often lose when they become non-drivers (Curl et al., 2014¹).

However, the feasibility of including a planning program in each town or city seems challenging (Bryanton et al., 2010 ${ }^{1}$ ). Therefore, an opportunity to incorporate driving cessation preparation into older adults' lives during later-life planning with health care professionals and legal professionals (Curl et al., 2014 ${ }^{1}$ ) is necessary. Driving cessation is often a difficult topic to discuss, as older adults felt that they are losing freedom and want to drive for as long as possible (Curl et al., 2014¹ $)$. The topic of driving cessation should be incorporated into later-life planning to help make it a normal topic to discuss with family and professionals (Curl et al., 2014¹').

City planning can prevent transportation gaps or services that do not benefit older adults, resulting in the need for AFC initiatives to modify transportation initiatives to better meet their needs (Bittner et al., 2011'; World Health Organization, 2007). Coordination between transportation services and programs for older adults is often up to the organizations alone (Klassen \& Allen, $2005^{1}$ ). Transportation often only comprises a small portion of program administrators' duties; therefore, they are less familiar with creating and budgeting for transportation programs (Bittner et al., 2011¹). The Gordon Head Recreation Centre Program, for example, found that there was a need to determine if it is transportation that acts as a barrier to isolated older adults participating in programs (Klassen \& Allen, 2005²). Enhanced communication between city planners and the public, including older adults, fostered better transportation planning (Bittner et al., 2011¹). For example, the WisDOT in the United States of America created a model for enhancing bus systems and providing taxi-sharing services where buses were unavailable, to improve transportation for older adults (Bittner et al., 2011¹). Additionally, the WisDOT also created the Interagency Council on Transportation Coordination (ICTC) to coordinate between the state and local levels (Bittner et al., 2011¹). Therefore, not unlike the AFC framework, transportation initiatives were adapted to fit the needs 
of Wisconsin's population of older adults while city planners, levels of government, and the public were involved in making transportation more suitable for older adults (Bittner et al., 2011', World Health Organization, 2007). The same is true for many administrative regions (municipalités régionales de comté [MRC]) in the Province of Québec in Canada, as indicated previously.

\section{Implications for Policy}

Older adults put their wishes to remain socially active and engaged aside if they needed to rely on others to drive them places, fearing that they will become a burden (Bryanton et al., 20101; Salazar, 1999¹). There should not have to be a choice. Everyone should be able to age in place and access programs and activities to maintain their social networks (Public Health Agency of Canada, $2010^{1}$ ). Service providers should recognize the role that public transportation policy plays in exacerbating social exclusion (Community Transportation Association of America, 20071) and creating barriers to recreational and physical activities (Chaudhury et al., 2012 ${ }^{1}$; Federal/ Provincial/Territorial Ministers Responsible for Seniors, 2007a1; Gagliardi et al., 20071; Klassen \& Allen, 20051; Levasseur et al., 2015 ${ }^{1}$; Mullen, 20051' White et al., 20101; Woldeyohannes, 2016ㄹ), social activities (Federal/ Provincial/Territorial Ministers Responsible for Seniors, 2007a ${ }^{1}$; Gagliardi et al., 2007¹ Klassen \& Allen, 2005;

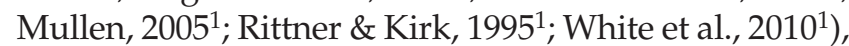
community events/resources (Bittner et al., 2011'; Federal/Provincial/Territorial Ministers Responsible

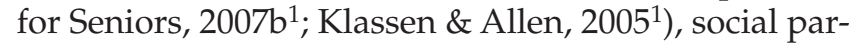
ticipation and engagement, support systems of family and friends (Bittner et al., 2011'; Federal/Provincial/ Territorial Ministers Responsible for Seniors, 2007a ${ }^{1}$;

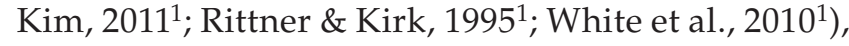
and programs (Chaudhury et al., 20121; Klassen \& Allen, 2005¹).

Listening to the concerns and needs of older adults could help policy makers determine the best ways to meet the transportation needs of older adults (Federal/ Provincial/Territorial Ministers Responsible for Seniors, $\left.2007 \mathrm{a}^{1}\right)$. Klassen \& Allen $\left(2005^{1}\right)$ recommended the use of steering committees, coordinators, and a formal coordination system among all transportation resources. This would allow for transportation to be taken into consideration when service providers, policy makers, and program and community developers. at both the municipal and provincial level make decisions about programs, housing, and facilities for older adults (Klassen \& Allen, 2005ํ). Community members, professionals, and service providers need to be consulted to better understand the needs of the community and how AFC initiatives can meet those needs (World Health Organization, 2007). Additionally, mobility challenges can be considered when designing communitybased programs and transportation to those programs (Chaudhury et al., 201211). More options for public and private transportation are needed; no single solution will suit all older adults with differing needs, and no single solution will suit each city/town with differing resources and transportation infrastructure (Bittner et al., 2011'; Federal/Provincial/Territorial Ministers Responsible for Seniors, 2007a ${ }^{1}$; Federal/Provincial/ Territorial Ministers Responsible for Seniors, 2007b ${ }^{1}$;

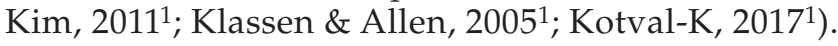

To determine the transportation needs of older adults, and how these can be addressed, older adults should be involved in discussions with policy makers (Federal/Provincial/Territorial Ministers Responsible for Seniors, 2007a $\mathrm{a}^{1}$ ). This idea reflects the general shift from quantitative models of aging, to more qualitative insights about social isolation, which provide a better understanding of the transportation needs of older adults (Curl et al., 2014¹).

\section{Implications for Research}

This scoping review found that few of the articles looked at public transportation initiatives from the AFC perspective. There is a need for research on public transportation initiatives to be connected to AFC research. The findings of this scoping review have suggested that public transportation is associated with social isolation and that AFCs have been an instrumental part of reducing social isolation (Emlet \& Moceri, 2012; WHO, 2007).

Furthermore, this scoping review indicated that there are differences in the transportation needs of older adults living in rural and urban communities (Bittner et al., 2011'; Bryanton et al., 2010 ; Chaudhury et al.,

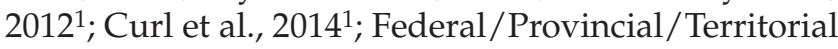
Ministers Responsible for Seniors, 2007a ${ }^{1}$; Gagliardi et al., 2007'; Federal/Provincial/Territorial Ministers Responsible for Seniors, 2007 ${ }^{1}$; Klassen \& Allen, 2005 ${ }^{1}$; Kotval-K, 20171; Public Health Agency of Canada, $2010^{1}$ ). Research should be conducted to examine the unique transportation needs that lead to social isolation in older adults from urban or rural communities and propose potential solutions. For example, rural older adults might be socially isolated by their location and lack of transportation options or availability altogether; therefore, interventions and initiatives that promote access to public transportation would need to be further explored to benefit rural areas (Bittner et al., 2011'; Kotval-K, 20171; Public Health Agency of Canada, $\left.2010^{1}\right)$. Meanwhile, urban older adults might have public transportation available to them and yet not use it; therefore, the question of how to make public transportation more suitable for older adults or how 
to provide older adults with information about their options for transportation would need to be further explored (Chaudhury et al., 20121; Bryanton et al., 20101 ${ }^{1}$ Carp, 19721 $)$. However, these articles included differing definitions of rural and urban areas, or they did not specify what was meant by this terminology. Therefore, a definition for a rural or urban area should be standardized prior to comparing the transportation needs of older adults in these areas.

\section{Limitations}

This scoping review did not capture the insight into public transportation initiatives that is available in the literature that is written in French or other languages. For example, excluding articles that were written in French omitted many articles from the Canadian Province of Québec. As was exemplified in the Discussion section, Québec has made exemplary progress in the coordination of transportation between different levels of government and transportation providers. The inclusion of French articles could have provided more insight into public transportation solutions that are geared toward rural communities as well as people with disabilities.

Additionally, this scoping review was conducted within a limited time frame, which restricted the number of sources that could be included in the database search phase to eight peer-reviewed and three grey literature sources. It is likely that not all existing literature that addresses this topic was examined. The time limitation also hindered the optional consultation with an expert panel, which might have yielded additional insight into the development of the research question and assistance with the contextualization of the research findings (Arksey \& O'Malley, 2005).

Although research from many countries was taken into consideration, the practice, policy, and research recommendations were made from a Canadian perspective. Therefore, these recommendations must be adapted to fit the transportation, health care, legal, and political systems that exist in the country to which they would be applied. The recommendations must be implemented within an existing infrastructure; therefore, there is not a single solution that will fit each country, city, or community. The goal of this scoping review was to provide a starting point for further discussion to be had and research to be conducted on this topic, which can fill the gaps in the existing literature and make further recommendations to benefit the aging population.

Another limitation is that there are many definitions of "rural area" and "urban area" that were used in these articles, if the articles defined the term at all. Because the final articles were inconsistent in their definition of a rural area, it is important to keep in mind that the recommendations for rural communities should be further explored depending on if a rural community is simply small or if it is also located far from a city, as lack of public transportation might be further exacerbated in a community that is further from a city (Federal/Provincial/Territorial Ministers Responsible for Seniors, $2007 \mathrm{a}^{1}$ ).

\section{Conclusion}

Initiatives that facilitate community engagement, development of social networks, and the establishment of meaningful relationships will not fulfil their intended purpose if older adults are unable to access these opportunities (World Health Organization, 2007). Although existing literature discussed barriers to the use of public transportation and improvements that need to be made to public transportation to benefit older adults (Adler \& Rottunda, 2006; Curl et al, 2014; Nordbakke \& Schwanen, 2015; World Health Organization, 2007), this scoping review provided insight into how public transportation might influence social isolation. Social isolation is a significant issue that affects older adults at a higher rate than any other age group; therefore, the practice, policy, and research recommendations may act as a starting point to prevent social isolation by using public transportation initiatives. These recommendations indicated that there is opportunity for public transportation to further prevent older adults' social isolation. Public transportation can act as a barrier to social engagement, but there is an opportunity for older adults' engagement in social, leisure, civic, work, and community activities and social networks to be facilitated through public transportation (Curl et al., 20141; Kim, 2011; White et al., 2010²).

\section{Supplementary Material}

To view supplementary material for this article, please visit https:/ / doi.org/10.1017/S0714980819000345

\section{Note}

1 Reference is part of the final articles selected for the scoping review.

\section{References}

Adler, G., \& Rottunda, S. (2006). Older adults' perspectives on driving cessation. Journal of Aging Studies, 20(3), 227-235. doi:10.1016/j.jaging.2005.09.003

Anderson, R. (2007). Thematic content analysis (TCA) descriptive presentation of qualitative data. Retrieved 6 May 2018 from http:/ / rosemarieanderson.com/wp-content/uploads / 2014/08/ThematicContentAnalysis.pdf

Arksey, H., \& O’Malley, L. (2005). Scoping studies: Towards a methodological framework. International Journal of Social Research Methodology, 8, 19-32. 
Béland, F., Zunzunegui, M.-V., Alvarado, B., Otero, A., \& del Ser, T. (2005). Trajectories of cognitive decline and social relations. The Journals of Gerontology. Series B, Psychological Sciences and Social Sciences, 60(6), P320-P330. https:/ / doi.org/10.1093/geronb/60.6.P320

Bittner, J., Fuchs, P., Baird, T., \& Smith, A. (2011). Addressing elderly mobility issues in Wisconsin. Retrieved 17 October 2017 from http: / www.wistrans.org/cfire/documents / CFIRE_04-05_Final_Report.pdf

Boden-Albala, B., Litwak, E., Elkind, M. S., Rundek, T., \& Sacco, R. L. (2005). Social isolation and outcomes post stroke. Neurology, 64(11), 1888-1892. doi: 10.1212/01. WNL.0000163510.79351.AF

Bryanton, O., Weeks, L. E., \& Lees, J. M. (2010). Supporting older women in the transition to driving cessation. Activities, Adaptation E Aging, 34(3), 181-195. doi: 10.1080/ 01924788.2010 .501483

Carp, F. M. (1972). Mobility among members of an established retirement community. The Gerontologist, 12(1), 48-56.

Chaudhury, H., Mahmood, A., Michael, Y. L., Campo, M., \& Hay, K. (2012). The influence of neighborhood residential density, physical and social environments on older adults' physical activity: An exploratory study in two metropolitan areas. Journal of Aging Studies, 26(1), 35-43. doi: 10.1016/j.jaging.2011.07.001

Chihuri, S., Mielenz, T. J., DiMaggio, C. J., Betz, M. E., DiGuiseppi, C., Jones, V. C., et al. (2016). Driving cessation and health outcomes in older adults. Journal of the American Geriatrics Society, 64(2), 332-341. doi: $10.1111 /$ jgs.13931

Cloutier-Fisher, D., Kobayashi, K. M., \& Smith, A. P. (2011). The subjective dimension of social isolation: A qualitative investigation of older adults' experiences in small social support networks. Journal of Aging Studies, 25(4), 407-414. doi: 10.1016/j.jaging.2011.03.012

Community Transportation Association of America. (2007). Tackling social exclusion: The role of public transport. Community Transportation, 25(4), 20. https://www. worldcat.org/title/rail/oclc/46346408

Coyle, C., \& Dugan, E. (2012). Social isolation, loneliness and health among older adults. Journal of Aging and Health, 24(8), 1346-1363. doi: 10.1177/0898264312460275

Curl, A. L., Stowe, J. D., Cooney, T. M., \& Proulx, C. M. (2014). Giving up the keys: How driving cessation affects engagement in later life. The Gerontologist, 54(3), 423-433. doi: 10.1093/geront/gnt037

Davey, J.A. (2007). Older people and transport: Coping without a car. Ageing and Society, 27, 49-65. https: / /www. cambridge.org/core/journals/ageing-and-society / article/older-people-and-transport-coping-withouta-car /EF2740D2898FF3E17E40D18292C78EA9

Emlet, C. A., \& Moceri, J. T. (2012). The importance of social connectedness in building age-friendly communities. Journal of Aging Research, 2012, 1-9. doi: $10.1155 / 2012 / 173247$

Federal/Provincial/Territorial Ministers Responsible for Seniors. (2007a). Age-friendly rural and remote communities: A guide. Retrieved 21 October 2017 from http:/ / www.phac-aspc.gc.ca/seniors-aines/alt-formats/pdf/ publications/public/healthy-sante/age_friendly_rural/ AFRRC_en.pdf

Federal/Provincial/Territorial Ministers Responsible for Seniors. (2007b). Working together for seniors: A toolkit to promote seniors' social integration in community services, programs and policies. Retrieved 21 October 2017 from http:/ / publications.gc.ca/collections/collection_ 2017/edsc-esdc/HS64-34-2007-eng.pdf

Fratiglioni, L., Wang, H. X., Ericsson, K., Maytan, M., \& Windblad, B. (2000). Influence of social network on occurrence of dementia: A community-based longitudinal study. The Lancet, 355(9212), 1315-1319. doi: 10.1016/ S0140-6736(00)02113-9

Gagliardi, C., Spazzafumo, L., Marcellini, F., Mollenkopf, H., Ruoppila, I., Tacken, M., et al. (2007). The outdoor mobility and leisure activities of older people in five European countries. Ageing \& Society, 27(5), 683-700. doi: 10.1017/S0144686X07006198

Gouvernement du Québec. (2010). Guide la prise de décision en urbanisme transport collectif. Retrieved 11 July 2018 from https: / / www.mamot.gouv.qc.ca/amenagement-duterritoire /guide-la-prise-de-decision-en-urbanisme / intervention/transport-collectif/

Kim, S. (2011). Assessing mobility in an aging society: Personal and built environment factors associated with older people's subjective transportation deficiency in the US. Transportation Research Part F, 14(5), 422-429. doi: 10.1016/j. trf.2011.04.011

Klassen, J., \& Allen, R. (2005). Transportation for older adults and persons with disabilities: Working together to accommodate diverse needs. In Bus $\mathcal{E}$ Paratransit Conference; American Public Transportation Association. Bus \& Paratransit Conference Proceedings: May 15-18, 2005, Columbus, OH (pp. 1-6). Washington, DC: American Public Transportation Association.

Kotval-K, Z. (2017). Transit accessibility for older adults in the Greater Lansing, Michigan region. Quality in Ageing and Older Adults, 18(3), 175-187. doi: 10.1108/QAOA-082016-0032

Levac, D., Colquhoun, H., \& O’Brien, K. K. (2010). Scoping studies: Advancing the methodology. Implementation Science, 5(69), 1-9. doi: 10.1186/1748-5908-5-69

Levasseur, M., Genereux, M., Bruneau, J. F., Vanasse, A., Chabot, E., Beaulac, C., et al. (2015). Importance of proximity to resources, social support, transportation and neighborhood security for mobility and social participation in older adults: Results from a scoping study. BMC Public Health, 15(503), 1-19. doi: 10.1186/s12889-015-1824-0 
Liddle, J. \& McKenna, K. (2003). Older drivers and driving cessation. British Journal of Occupational Therapy, 66(3), 125-132. https://journals.sagepub.com/doi/10.1177/ 030802260306600307

Mullen, K. (2005). How does access to public transit affect the quality of life of seniors over 75 in Ottawa? A qualitative analysis. Masters Abstracts International, 44-03, 1197. https:/ / curve.carleton.ca/36e5772c-f257-49ec-a534-c7ecfd06a8ea

Nicholson, N. (2009). Social isolation in older adults: An evolutionary concept analysis. Journal of Advanced Nursing, 65(6), 1342-1352. doi: 10.1111/j.1365-2648.2008.04959.x

Nicholson, N. (2012). A review of social isolation: An important but underassessed condition in older adults. The Journal of Primary Prevention, 33(2-3), 137-152. doi:10.1007/ s10935-012-0271-2

Nordbakke, S., \& Schwanen, T. (2015). Transport, unmet activity needs and wellbeing in later life: Exploring the links. Transportation, 42(6), 1129-1151. doi:10.1007/ s11116-014-9558-x

Public Health Agency of Canada. (2010). Chapter 4: The Chief Public Health Officer's report on the state of public health in Canada 2010 - Setting conditions for healthy aging. Retrieved 9 October 2017 from https://www. canada.ca/en/public-health/corporate/publications/ chief-public-health-officer-reports-state-publichealth-canada/annual-report-on-state-public-healthcanada-2010/chapter-4.html

Ragland, D. R., Satariano, W. A., \& MacLeod, K. E. (2005). Driving cessation and increased depressive symptoms.
The Journals of Gerontology: Series A, 60(3), 399-403. https:/ / doi.org/10.1093/gerona/60.3.399

Rittner, B., \& Kirk, A. B. (1995). Health care and public transportation use by poor and frail elderly people. Social Work, 40(3), 365-373. http://www.jstor.org/ stable/23718091?seq=1\#page_scan_tab_contents

Salazar, B. P. (1999). Determinants of public transportation utilization by non-disabled senior citizens: An extension of Fishbein and Ajzen's theory of reasoned action. Ann Arbor, MI: UMI Dissertation Services.

Statistics Canada. (2008). Structure and change in Canada's rural demography: An update to 2006. Rural and Small Town Canada Analysis Bulletin, 7(7), 1-29. http:// www.statcan.gc.ca/pub/21-006-x/21-006-x2007007eng.pdf

White, D. K., Jette, A. M., Felson, D. T., Lavalley, M. P., Lewis, C. E., Torner, J. C., et al. (2010). Are features of the neighborhood environment associated with disability in older adults? Disability and Rehabilitation, 32(8), 639-645. doi: 10.3109/09638280903254547

Woldeyohannes, H. (2016). A case for the need for standards for older adult recreation programs: A literature review. Retrieved 14 October 2017 from http:/ /highfive.org/sites/default / files /OlderAdultStandardLitReview\%20Aug\%2016. pdf

World Health Organization. (2007). Global age-friendly cities: A guide. Retrieved 24 September 2017 from http:/ / www.who.int/ageing/publications/Global_age_ friendly_cities_Guide_English.pdf 